\title{
Molecular study of the rhodopsin gene in retinitis pigmentosa patients in the Basque Country
}

\author{
A I Alvarez, E Arostegui, R Martin, M Duran, M L Onaindia, M Molina, M I Tejada
}

\begin{abstract}
Retinitis pigmentosa (RP) is a degenerative disorder affecting the outer segment of the retina and leading to night blindness and progressive visual field loss. The rhodopsin gene encodes a photolabile pigment located in the rod outer segments constituting around $80-90 \%$ of its protein content and is the initiation point for the visual cascade upon absorption of a single photon. Seventy-five unrelated, isolated RP families in the Basque Country, with at least one affected member, were diagnosed at our hospital after ophthalmic examination and electroretinogram analysis. The patients received genetic counselling according to their individual case based on their clinical diagnosis. The modes of inheritance found from pedigree studies were the following: $20 \%(15 / 75)$ were classified as autosomal dominant retinitis pigmentosa (ADRP), 17.33\% (13/75) were autosomal recessive (ARRP), 2.66\% (2/75) were unclassified (NC), and $60 \%(45 / 75)$ were sporadic cases (SCRP). From these families, 75 unrelated and affected index cases together with 22 affected relatives and 42 unaffected relatives were screened for mutations in the rhodopsin gene by GC clamped denaturing gradient gel electrophoresis. Our results showed that five ADRP, three ARRP, 15 SCRP, and one NC families had alterations in this gene. Only three of these alterations, that is $4 \%(3 / 75)$ (95\% CL 0-8), appeared to be responsible for the disease. This represents a lower percentage than the $10 \%$ previously re-
\end{abstract}

diagnosed with isolated RP. Most of these families were identified by the Association for RP Affected Individuals in the Basque Country. After their clinical diagnosis, based on ophthalmic and neurological examination, the patients were referred for genetic counselling and molecular analysis.

Currently, more than 20 loci have been linked to $R P$, from which six genes have been isolated. One of these six, the rhodopsin gene, encodes a photolabile pigment constituting $80-90 \%$ of the protein content in rod photoreceptor outer segments. ${ }^{1}$ This protein is responsible for the initiation of the visual transduction cascade upon the incidence of a photon of light. The rhodopsin gene is thought to be the most common cause of RP, with mutations being reported as responsible for $20-30 \%$ of ADRP, ${ }^{3}$ some ARRP, ${ }^{45}$ and a few cases of SCRP. ${ }^{6}$ Altogether, rhodopsin mutations have been reported to account for $10 \%$ of all $\mathrm{RP} .^{2}$

Considering the significance of this gene, we decided to carry out screening for rhodopsin mutations among our RP population.

\section{Materials and methods}

CLINICAL EXAMINATION

The patients were ophthalmologically examined for visual acuity, eye tension, and lens opacity, and given a complete fundus examination and visual field analysis by Humphrey computer. For each patient, personal data regarding age of onset, first and present symptoms of RP, and family information were also compiled. Electrophysiological analysis was based on electroretinogram (ERG) with Ganzfield stimulation through scotopic and phototopic conditions, as well as visual evoked potentials (VEP) and acoustic evoked potentials (AEP).

\section{PATIENTS}

In our Genetic Unit, we classified 75 unrelated isolated RP families with at least one affected member based on the modes of inheritance: $20 \%(15 / 75)$ ADRP, $17.33 \%$ (13/75) ARRP, $2.66 \%(2 / 75) \mathrm{NC}$, and $60 \%(45 / 75)$ SCRP. It is interesting to note that none of the families in this study seemed to show an X linked RP pattern by extended family history of three or more generations. In the SC cases we included all pedigrees with only one affected member, although there was consanguinity in some of them, as long as there were no other affected family members or other features suggestive of a different mode of transmission.

Out of these families, 75 unrelated and affected index cases were screened together with 22 affected relatives and 42 unaffected relatives to search for mutations in the \footnotetext{
ported.

(F Med Genet 1998;35:387-390)

Keywords: gene mutation; retinitis pigmentosa; rhodopsin

Retinitis pigmentosa (RP) is a degenerative disorder affecting the outer segment of the retina and leads to night blindness and progressive visual field loss. It can occur as isolated RP or associated with a syndrome and affects an average of 1 in 4000 of the white population. ${ }^{1}$ This disorder is very heterogeneous both clinically and genetically. Inheritance of RP can be autosomal dominant (AD), autosomal recessive (AR), or $X$ linked (XL), and a few cases have been reported as mitochondrial or digenic; however, most of the cases are sporadic (SC). ${ }^{2}$

Of all the families with eye disorders who came to our hospital over a period of three years, 75 of them had at least one member

Received 4 April 1997 Revised version accepted for publication

10 November 1997

Correspondence to: Dr Tejada.

Genetics Unit, Basurto
Hospital, Avda
Montevideo 18, 48013
Bilbao, Spain
A I Alvarez
M Duran
M L Onaindia
M Molina
M I Tejada
Ophthalmology
Service, Basurto
Hospital, Bilbao, Spain
E Arostegui
Neurophysiology
Service, Basurto
Hospital, Bilbao, Spain
R Martin
Correspondence to:
Dr Tejada.
Received 4 April 1997
Revised version accepted for
publication
10 November 1997
}


Table 1 RP families in the Basque Country with alterations in the rhodopsin gene

\begin{tabular}{|c|c|c|c|c|c|}
\hline $\begin{array}{l}\text { Mode of } \\
\text { transmission }\end{array}$ & $\begin{array}{l}\text { Total No of } \\
\text { families }\end{array}$ & $\begin{array}{l}\text { No of families } \\
\text { with rhodopsin } \\
\text { alteration }\end{array}$ & Family lab name & Class of alteration & Rhodopsin alteration \\
\hline ADRP & 15 & $5(33.3 \%)$ & $\begin{array}{l}\text { F. } 8 \\
\text { F. } 21\end{array}$ & $\begin{array}{l}\text { Causative polymorphism } \\
\text { Causative silent mutation } \\
\text { polymorphism }\end{array}$ & $\begin{array}{l}\text { AG-AT nt } 5167 \text { C-A nt } 5321 \\
\text { A211G (His-Arg) C160A } \\
\text { (Thr) C-T nt } 3982+C-A \text { nt } \\
5321\end{array}$ \\
\hline ARRP & 13 & $3(23.0 \%)$ & $\begin{array}{l}\text { F. } 59,72,93 \\
\text { F. } 31\end{array}$ & $\begin{array}{l}\text { Polymorphism } \\
\text { Polymorphism } \\
\text { Polymorphism }\end{array}$ & $\begin{array}{l}\text { C-T nt } 3982+C-A \text { nt } 5321 \\
\text { G-T nt } 682 \\
\text { C-T nt } 3982+C-A \text { nt } 5321\end{array}$ \\
\hline & & & F. 71,81 & Polymorphism & C-T nt $3982+C-A$ nt 5321 \\
\hline SCRP & 45 & $15(33.3 \%)$ & $\begin{array}{l}\text { F. } 49 \\
\text { F. } 82 \\
\text { F. } 86 \\
\text { F. } 4,18,20,44,50, \\
\quad 52,53,54,57,63, \\
70,85\end{array}$ & $\begin{array}{l}\text { Causative polymorphism } \\
\text { Polymorphism } \\
\text { Silent mutation } \\
\text { Polymorphism }\end{array}$ & $\begin{array}{l}\text { C23T (Pro-Leu)A-G nt } 269 \\
\text { C-A nt 5321 } \\
\text { C160A (Thr) } \\
\text { C-T nt 3982+C-A nt } 5321\end{array}$ \\
\hline $\begin{array}{l}\text { NC } \\
\text { Total }\end{array}$ & $\begin{array}{r}2 \\
75\end{array}$ & $\begin{array}{r}1(50 \%) \\
24(32 \%)\end{array}$ & F. 48 & Polymorphism & C-T nt 3982 \\
\hline
\end{tabular}

$\mathrm{F}=$ family, $\mathrm{nt}=$ nucleotide.

rhodopsin gene by GC clamped denaturing gradient gel electrophoresis (DGGE).

All the index cases were karyotyped on peripheral blood lymphocytes.

The clinical symptoms of our patients were variable but quite homogeneous within the same inheritance group. They all showed typical night blindness with loss of peripheral visual field and the presence of additional features in the fundus (cataracts, retinal vessel attenuation, and retinal drusen, etc). The symptoms and clinical findings were less severe in the dominant group than in the recessive group.

\section{MOLECULAR ANALYSIS}

Genomic DNA was extracted from whole blood lymphocytes through a "salting out" procedure. Six segments of the rhodopsin gene consisting of the five exons together with adjacent intronic sequences were amplified using the polymerase chain reaction (PCR) and primers that contained a 40 base pair GC clamp, according to the method of Sheffield et $a l^{8}$ modified for a final volume of $50 \mu \mathrm{l}(5 \mu \mathrm{l}$ of $10 \times$ buffer supplied by Boehringer-Mannheim, $75 \mathrm{nmol}$ of a dNTP mix, 25 pmol of each primer, DMSO 8-10\%, $1.30 \mathrm{U}$ Taq polymerase (also supplied by Boehringer-Mannheim), $60-180 \mathrm{ng}$ of human genomic DNA, and $36 \mu$ of water). PCR conditions consisted of a denaturation step at $94^{\circ} \mathrm{C}$ for four minutes, 40 cycles with denaturation at $94^{\circ} \mathrm{C}$ for 30 seconds, annealing at $55^{\circ} \mathrm{C}$ for 30 seconds, and elongation at $72^{\circ} \mathrm{C}$ for 30 seconds followed by two final steps of denaturation at $94^{\circ} \mathrm{C}$ and reannealing at $72^{\circ} \mathrm{C}$ for five minutes each. Denaturing gradient gel electrophoresis (DGGE) was performed following the methods of Myers et al. ${ }^{9-11}$ PCR products that showed altered DGGE migration with the appearance of more than one band were digested with restriction endonuclease or sequenced or both.

Each sample was digested using $K s p I$ for RHO (1A), SmaI for RHO (1B), RsaI for RHO (3), and FokI for RHO (5). A purification step using the Promega Magic Minipreps $\mathrm{Kit}$ according to manufacturer's instructions was performed before DNA sequencing; the resulting purified PCR products were directly sequenced by the dideoxy chain termination method using the fmol cycle sequencing kit from Promega.

\section{Results}

We found an altered DGGE pattern in five ADRP, three ARRP, 15 SCRP, and one NC families (table 1). We classified these DNA alterations into three categories: (1) mutations that could be responsible for the disorder, (2) silent mutations, and (3) polymorphisms (table $1)$. Every alteration was found in the heterozygous state.

In the first group, we found a total of three DNA mutations, two in the ADRP group and one in a SCRP case. The two changes in the ADRP families were an AG-AT substitution at position 5167 in the acceptor splice site of intron $4,{ }^{12}$ and an A-G transversion in codon $211-\mathrm{RHO}$ (3) which leads to the amino acid change His211Arg. ${ }^{13}$ The third mutation present in a family first classified as SCRP was a C-T transition in the second nucleotide of codon 23-RHO (1A), which caused a Pro23Leu change (manuscript in preparation).

In the second group, we found two families (one $\mathrm{AD}$ and the other SC) with a C-A substitution (Thr) in codon 160-RHO (2) which produces a silent mutation. ${ }^{13}$

In the third group, we saw the previously described polymorphisms $\mathrm{C}-\mathrm{T}$ at nucleotide 3982-RHO (3) ${ }^{14}$ and C-A at nucleotide 5321 within RHO (5) ${ }^{14}$ in five ADRP, three ARRP, and 12 SCRP families. One NC family only had the C-T polymorphism at position 3982 and a SCRP family had only the C-A polymorphism at position 5321. In addition, we found a G-T polymorphism at nucleotide 682 in one ARRP family; to our knowledge this is the first time this polymorphism has been described. Finally, we also saw the previously described A-G polymorphism at nucleotide $269-\mathrm{RHO}$ $(1 \mathrm{~A})^{15}$ in the family with the third mutation. Table 2 shows the allelotypes and familial frequencies of all these polymorphisms.

\section{Discussion}

The 75 families diagnosed with isolated RP and studied in this work were collected at our hospital over a period of three consecutive years. The different modes of inheritance were 
Table 2 Allelotypes in RP affected families within the Basque Country and familial frequencies

\begin{tabular}{|c|c|c|c|c|c|}
\hline Num fam (fam freq) & Inheritance classification & RHO (3) & RHO (5) & $R H O(1 A)$ & $R H O(1 B)$ \\
\hline $52(69.3 \%)$ & $\begin{array}{l}\text { AD:10/15 (66.6\%) } \\
\text { AR:10/13 (77.9\%) } \\
\text { SC:31/45 (68.8\%) } \\
\text { NC:1/2 (50\%) }\end{array}$ & $-1-$ & $-1-$ & $-1-$ & $-1-$ \\
\hline $18(24 \%)$ & $\begin{array}{l}\text { AD:4/15 (26.6\%) } \\
\text { AR:3/13 (23.0\%) } \\
\text { SC:12/45 (26.6\%) }\end{array}$ & $-/ \mathrm{C} 3982 \mathrm{~T}$ & $-/ \mathrm{C} 5321 \mathrm{~A}$ & $-1-$ & $-1-$ \\
\hline $2(2.66 \%)$ & $\begin{array}{l}\text { AD:1/15 (6.6\%) } \\
\text { SC:1/2 (2.2\%) }\end{array}$ & $-1-$ & $-/ \mathrm{C} 5321 \mathrm{~A}$ & $-1-$ & $-1-$ \\
\hline $1(1.3 \%)$ & NC: $1 / 2(50 \%)$ & $-/ C 3982 \mathrm{~T}$ & $-1-$ & $-1-$ & $-1-$ \\
\hline $1(1.3 \%)$ & SC: $1 / 45(2.2 \%)$ & $-1-$ & $-1-$ & $-/ \mathrm{A} 269 \mathrm{G}$ & $-1-$ \\
\hline $1(1.3 \%)$ & AR:1/13 (7.69\%) & $-/ C 3982 \mathrm{~T}$ & $-/ \mathrm{C} 5321 \mathrm{~A}$ & $-1-$ & $-/ G 682 T$ \\
\hline
\end{tabular}

established at our genetic counselling department after exhaustive interviews with both patients and relatives, generating pedigrees of three and sometimes four generations. Considering this information, the classification was based on the clinical symptoms; therefore, the frequencies given in our results cannot be considered definitive. For instance, there are two SC cases (as described in Patients) which could be classified as AR transmission because there is consanguinity, but we have classified them as SC since there are no other affected sibs and we have not been able to study homozygosity. The apparent lack of X linked RP families is also interesting. In two of the families classified as $A R$, we found in the offspring two affected brothers and no affected sisters. Our decision to classify them as AR is based on the following criteria. (1) In three generations there is no other affected male through maternal transmission and (2) there appears to be consanguinity in their parents. Therefore, the apparent lack of $\mathrm{X}$ linked RP in our sample could be because of regional and geographical differences described in the Basque population on several occasions. ${ }^{16-18}$

Regarding the DNA alterations found by DGGE, we have considered those that seem to be responsible for $\mathrm{RP}$, that is, all the anomalies found in the coding region of the protein that were present in the affected members and not in the unaffected. These include the missense mutations (fam 21-RHO (3) and fam 49RHO (1A)) and the splice site mutation (fam 8-RHO (5)). In all cases, it seems obvious that the DNA alteration could affect the protein structure and therefore lead to RP. As discussed previously, ${ }^{1213}$ the most problematical case is family 49 who have the Pro23Leu mutation not only in the subject with RP but also in his three at present asymptomatic children (paper in preparation). This is interesting because the patient was first classified as SC with no other affected members, but this mutation has also been described as responsible for one case of ADRP. ${ }^{19}$ Since our patient does not have a previous family history of RP and experienced his first symptoms in his forties, we surmise that this could be a de novo mutation and that his children (now in their thirties) may show symptoms of the disorder later. This family may also be $\mathrm{AD}$ with incomplete penetrance, since Sandberg et $a l^{20}$ have shown that patients with an intradiscal mutation seem to have less severe features of RP than patients with rhodopsin mutations in other domains. Finally, the mutated allele could be recessive with the presence of another undetected and mutated second allele. For this potentially digenic model, we have eliminated $\mathrm{RDS} /$ pheripherin as the second gene as no mutations were found in this gene in this family. Hopefully, future follow up in the clinical study of this family will determine the exact nature of this case.

To summarise, we report that $13.33 \%(2 / 15)$ or $18.75 \%(3 / 16)$ of ADRP families in the Basque Country have a rhodopsin gene defect that seems to be responsible for the disorder, the latter percentage being closer to the $20-30 \%$ reported by other authors. ${ }^{815}$

All the DNA mutations found in the affected population are individual point mutations seen in individual families. In our total sample, the percentage of defects in the rhodopsin gene that could be responsible for $\mathrm{RP}$ is $4 \%(3 / 75)(95 \% \mathrm{CL} 0-8)$, which is a little lower than the reported figure of $10 \%$ by other authors. Considering the allelic heterogeneity of this gene, this could be because of a genetically distinct population; however, more exhaustive studies will be necessary to confirm this as well as to elucidate the pathology of RP.

Regarding the group of DNA alterations that do not seem to be responsible for $R P$, we have included here: (1) all alterations present in the non-coding region of the protein, (2) changes not altering the amino acid sequence, and (3) changes that did not cosegregate with the disorder within families. Some of these have already been found with controls in other studies. It should be noted that $24 \%$ of the patients (table 2) with the polymorphism at position 3982 also had the one at nucleotide 5321. As we can see in table 2 , this percentage is similar in the three inheritance classes. This could suggest a possible founder effect for the polymorphism among apparently nonrhodopsin RP patients, but with some reservations. Cosegregation is inconsistent. For example, the index case of fam 21 had the two polymorphisms together with a silent mutation in exon 2, and a mutation that seems to be responsible for the disease in exon 3 (table 1). The two mutations cosegregate with the polymorphism in RHO (3) but not with the polymorphism in RHO (5), which the patient inherited from her father. ${ }^{13}$ Also, we found no homozygotes, which is unexpected based on the high frequency of heterozygotes. For the RHO (3) polymorphism, the frequency is 
$13.3 \%$ (20/150 chromosomes) and for RHO (5) polymorphism $14 \%(21 / 150)$ (table 2 ). These figures are quite similar to other studies in the Spanish population ${ }^{21}$ and by different authors. ${ }^{14}$

We would like to thank the Foundation ONCE/National Federation for the RP Affected People for their contribution. We would also like to thank all the patients and relatives participating in this study. We specially thank D Victor Barrera for his collaboration in the informatics field, and also $\mathrm{Dr}$ Miguel Carballo and D Carlos Reig for their collaboration in the sequenc(1) Investigaciones Cientificas (FIS No 94/0854).

1 Nathans J, Merbs SL, Sung CH, Weitz CJ, Wang Y Molecular genetics of human visual pigments. Annu Rev Genet 1992;26:403-24.

2 Dryja T, Li T. Molecular genetics of retinitis pigmentosa. Hum Mol Genet 1995;4:1739-43.

3 Macke JP, Davenport CM, Jacobson SG, et al. Identification Macke JP, Davenport CM, Jacobson SG, et al. Identification
of novel rhodopsin mutations responsible for retinitis pigmentosa: implications for the structure and function of rhodopsin. Am ₹ Hum Genet 1993;53:80-9.

4 Rosenfeld P, Cowley G, McGee T, Sandberg M, Berson E Dryja T. A null mutation in the rhodopsin gene causes rod photoreceptor dysfunction and autosomal recesive retinitis pigmentosa. Nat Genet 1992;1:209-13

5 Kumaranickavel G, Maw M, Denton MJ, et al. Missense rhodopsin mutation in a family with recesive RP. Nat Genet 1994;8:10-11.

6 Reig C, Antich J, Gean E, et al. Identification of a novel rhodopsin mutation (Met-44-Thr) in a simplex case of retinitis pigmentosa. Hum Genet 1994;3:283-6.

7 Alvarez AI, Duran M, Molina M, et al. Molecular screening of the rhodopsin gene in 65 retinitis pigmentosa patients of the rhodopsin gene in 65 retinitis pigmentosa patients from the Basque Country. Abstract, 46th Annual Meeting
of the American Society of Human Genetics. 29 October-2 of the American Society of Human Genetics. 29 October-2

8 Sheffield VC, Fishman GA, Beck JS, Kimura AE, Stone EM. Identification of novel rhodopsin mutations associated with retinitis pigmentosa by GC-clamped denaturing gradient gel electrophoresis. Am f Hum Genet 1991;49: 699-706.

9 Myers RM, Maniatis T, Lerman LS. Detection and localization of single base changes by denaturing gradient gel elec- trophoresis. In: Wu R, ed. Methods in enzymology. Vol 55. New York:Academic Press, 1987:501-27.

10 Myers RM, Sheffield VC, Cox DR. Detection of single base changes in DNA: ribonuclease cleavage and denaturing gradient gel electrophoresis. In: Davies KE, ed. Genome analysis. A practical approach. Oxford: IRL Press, 1988:95139.

11 Myers RM, Sheffield VC, Cox DR. Mutation detection by PCR, GC clamps and denaturing gradient gel electrophoresis. In: Ehrlich HA, ed. PCR technology. New York: Stockton, 1989:71-8.

12 Reig C, Alvarez AI, Tejada MI, et al. A new mutation in the 3 -acceptor splice site of intron 4 in the rhodopsin gene associated with autosomal dominant retinitis pigmentosa. Hum Mutat 1996;8:93-4.

13 Reig C, Llecha N, Antich J, et al. A missense mutation (His211 Arg) and a silent (160 Thr) mutation within the rhodopsin gene in a Spanish autosomal dominant retinitis pigmentosa family. Hum Mol Genet 1994;3:195-6.

14 Dryja TP, McGee TL, Hahn LB, et al. Mutations within the rhodopsin gene in patients with autosomal dominant retinitis pigmentosa. N Engl f Med 1990;323:1302-7.

15 Sung CH, Davenport CM, Hennessey JC, et al. Rhodopsin mutations in autosomal dominant retinitis pigmentosa. Proc Natl Acad Sci USA 1991;88:6481-5.

16 Iriondo $M$, Barbero MC, Izaguirre N, Manzano C. Data on six short-tandem repeat polymorphisms in an autochthonous Basque population. Hum Hered 1997;47:131-7.

17 Esparza B, Pestoni C, Martin MD, Merino F, Carracedo A Distribution of the HLA-DQA1 polymorphism in the population of the Basque Country (Spain). Gene Geogr 1995;9:53-8.

18 Manzano C, Moral P, De la Rua C, Moreno P. Serum protein polymorphism (GC, TF, and PI subtypes) in the Basque population of Alava. Hum Hered 1993;43:121-5.

19 Dryja T, Hahn L, Cowley G, McGee T, Berson E. Mutation spectrum of the rhodopsin gene among patients with autosomal dominant retinitis pigmentosa. Proc Natl Acad Sci USA 1991;88:9370-4.

20 Sandberg MA, DiFranco CW, Dryja TP, Berson EL. Clinical expresion correlates with location of rhodopsin mutation in dominant retinitis pigmentosa. Invest Ophthalmol Vis Sci 1995;36:1934-42.

21 Ruiz A, Teijeira S, Rodriguez MJ, et al. XVIII Spanish Meeting for Human Genetics. Spanish Association of Human Genetics meeting, 30 October-3 November, 1995, Sevilla, Spain. 